\title{
Testing the Efficient Market Hypothesis in an Emerging Market: Evidence from Forex Market in Mauritius
}

\author{
Lydie Myriam Marcelle Amelot, Subadar Agathee Ushad, Matthew Lamport
}

Finance and Accounting Department, Faculty of Law and Management, University of Mauritius, Reduit, Mauritius

Email: lydieamelot@yahoo.com,u.subadar@uom.ac.mu,m.lamport@uom.ac.mu

How to cite this paper: Amelot, L.M.M., Ushad, S.A. and Lamport, M. (2017) Testing the Efficient Market Hypothesis in an Emerging Market: Evidence from Forex Market in Mauritius. Theoretical Economics Letters, 7, 2104-2122.

https://doi.org/10.4236/tel.2017.77143

Received: October 19, 2017

Accepted: December 9, 2017

Published: December 12, 2017

Copyright (c) 2017 by authors and Scientific Research Publishing Inc. This work is licensed under the Creative Commons Attribution International License (CC BY 4.0).

http://creativecommons.org/licenses/by/4.0/

\begin{abstract}
The present study investigates the efficiency of the forex market based on the theory of the Efficient Market Hypothesis in Mauritius, a well-diversified and emerging economy in the African region. Hence, this study considers the case of Mauritian forex market nominal spot rate daily data namely EUR/MUR, USD/ MUR, GBP/ MUR and JPY/ MUR over a time period of 5 years ranging from 2012 to 2016. The technique used for analysis is firstly concentrated on the use of Augmented-Dickey Fuller (ADF) and Philips Peron (PP) unit root to test the weak-form of efficiency and secondly, the Johansen Cointegration Test, the Granger Causality Test and Variance Decomposition are utilized to examine the existence of semi-strong form efficiency in the Mauritian foreign exchange market. Results indicated that the unit root test tested by ADF and PP unit root test support the weak form market as it follows a random walk process. Secondly, the Johansen Cointegration test reveals that there is no long run relationships among foreign exchange variables. However, the Granger causality test confirmed the existence of unidirectional and bidirectional relationships among the various exchange rates. Moreover, the Variance Decomposition confirmed the presence of long run co-movements among the exchange rates. Therefore, both tests fail to support the semistrong form market. This means that one exchange rate can predict one or more exchange rates which is against the semi-strong form market hypothesis. Therefore, it is deduced that the foreign market is efficient in the weak-form but is inefficient in the semi-strong form in Mauritius.
\end{abstract}

\section{Keywords}

Efficient Market Hypothesis, Forex Market, Stock Exchange of Mauritius, Emerging Markets 


\section{Introduction}

In financial economics, the Efficient Market Hypothesis theory has been a great debate since its inception in the 1960s at the University of Chicago. At present, it is becoming more prominent as investors are more engaged in diversification of investment products worldwide. However, EMH was criticized because even though this theory was held by academics, it was a controversy in applied finance resulting to anomalies Le Baron [1]. On the other hand, it was seen that the theory should be based upon the disequilibrium of the market. The theory of market efficiency is one of the most important concept that was discussed in literature. An efficient market is one in which prices of securities fully reflect all known information quickly and accurately Tahir [2]. Fama [3] divided market efficiency into three forms namely weak form, semi-strong form and the strong form market efficiency. In its weak form, efficiency suggests that the information available reflects only the history of prices or returns, thus investors cannot earn abnormal profits. Hence, stock prices/currency prices (spot exchange rates) will exhibit a random walk process. Semi-strong efficiency states that prices reflect the information available to all market individuals. In its strong form, efficiency refers to prices that reflect inside information in addition to past prices and publicly available information [3], Fama [4].

Market efficiency plays a major role in the foreign exchange market for investors, financial analysts, financial managers and to all relevant stakeholders using foreign exchange. Fama [5] stated that a foreign exchange market is efficient if fully reflects all available information. In fact, the EMH is considered the cornerstone of modern foreign exchange theory, and it takes into account both the rational expectations hypothesis and the risk-neutral behavior of investing agents, [6]. In addition, foreign exchange efficiency is concentrated on the different trading strategies producing excess returns and if currency prices reflect available information. To continue further, investors are motivated by the profit opportunities of overvalued and undervalued currencies. Thus, investment analysts' search for mispriced currencies and their subsequent trading makes the market efficient and causes prices to reflect intrinsic values Chowdhry [7]. Moreover, an efficient exchange market requires minimal government intervention and its investors cannot gain abnormal returns from foreign exchange transactions. On the contrary, foreign exchange inefficiency may lead to the development of exchange rate movements and provides opportunities for profitable exchange transactions Wickremasing he [8]. If a stock/currency market is inefficient, (the pricing system may not assure the efficient allocation of capital in an economy which impacts negatively to the aggregate economy) Hamid and Akash [9].

The purpose of the study is to investigate the efficiency of the Mauritian forex market based on the theory of Efficient Market Hypothesis. As a developing country, Mauritius has become an emerging market with a lot of potential of investment that gets an attention for financial analysts, investors and financial 
managers need to rethink about their buying and selling recommendations in forex. In fact, Foreign Exchange Reserves in Mauritius increased to 5262.10 USD Million in June from 5158 USD Million in June of 2017. Mauritian Foreign Exchange Reserves averaged 2295.92USD Million from 1999 until 2017, reaching a high of 5262.62 USD Million in May of 2017 and a record low of 637.50 USD Million in October of 2000. In the long-term, the Mauritius Foreign Exchange Reserves is projected to trend around 4935.22 USD Million in 2020.Foreign Exchange Reserves in Mauritius is reported by the Bank of Mauritius. Hence, this study considers the case of the Mauritian forex market namely EUR/MUR, USD/ MUR, GBP/MUR, JPY/MUR and AUD/MUR over a time frame of 5 years ranging from 2012 to 2016 as they are more actively traded. The importance here is to understand the main theories of market efficiency related to foreign exchange and how it is applicable and predictable in Mauritius. Therefore, the technique used for analysis is concentrated on the use of Augmented-Fuller Test and Philips Peron Test to examine the existence of a weak form market efficiency in Mauritian forex. Secondly, the semi-strong form market efficiency is also tested by using the Granger causality test.

Another motive for conducting this study is that most research work performed on testing the efficiency of the markets was based mainly on the efficiency of stock and share prices. For instance, Fowdar [10] and Fauzel [11] studied the efficiency of the stock exchange of Mauritius and Development and Enterprise Market in Mauritius. However, it was noted that Kisto et al. [12] studied the efficiency of foreign exchange market in Mauritius but the study was concentrated only on the testing of the weak form market efficiency based on using only a single currency. Therefore, based according to the author's knowledge, there was no other studies till present in Mauritius where the theory of EMH based on the weak form and semi-strong form is being tested using several foreign currencies data.

Hence, the study to be analysed is concerned with the following objectives:-

$>$ To investigate the existence of the weak-form method of efficiency in the Mauritian foreign exchange market

$>$ To analyse the existence of the semi-strong form method of efficiency in the Mauritian foreign exchange market

The plan of the study is outlined as follows: Section II provides a review of previous research studies. The research methodology and data are discussed in Section III. Section IV presents the empirical results of this study in the light of literature review and researcher's opinions. Subsequently, Section V summarizes the findings and presents the conclusion and policy implications.

\section{Literature Review}

The recent studies that were performed to indicate the efficiency of the foreign exchange market and the use of various types of econometric techniques and data frequencies are described to explain this theory. 
Hakio [13] examined five exchange rates against US dollar for a period of five years during the mid 1970s. The result of this study implied the rejection of the EMH.

[5] examined efficiency in nine exchange rates (nine currencies against US dollar), the use OLS estimation confirmed that the market efficiency hypothesis was not accepted because of a time-varying risk premium.

Coleman [14] found unit roots in major foreign exchange rates, and claimed that foreign exchange rates followed a random walk process.

Aron [15] surveyed efficiency tests on various African foreign exchange markets using the cointegration methodology. Specifically for South Africa, Aron tested the weak form of efficiency market hypothesis by a variant of the Martingale model and found that the exchange rate returns were predictable by past values of exchange rates, thus the market is inefficient in its weak form for the period 1979:2 to 1995:3.

[8] tested weak and semi-strong form efficiency of the foreign exchange market in Sri Lanka during the recent float using six bilateral exchange rates. Weak-form efficiency was examined using unit root tests while semi-strong form efficiency was tested using co-integration, Granger causality tests and variance decomposition analysis. Results indicated that the Sri Lankan foreign exchange market was consistent with the weak-form of the Efficient Market Hypothesis. However, the results provided evidence against the semi-strong version of the Efficient Market hypothesis.

Aroskar et al. [16] found strong evidence of market inefficiency in the EMS currencies before the introduction of the Euro, in which parities were strongly fixed.

Cooray and Wickremasinghe [17] examined the efficiency in the stock markets of India, Sri Lanka, Pakistan and Bangladesh using monthly for the period January 1996 to January 2005. The Augmented Dickey Fuller (ADF), the Phillips-Perron (PP), the Dickey-Fuller Generalized Least Square (DF-GLS) and Elliot-Rothenberg-Stock (ERS) tests were used to examine weak-form stock market efficiency and the results were confirmed by the classical unit root tests. Cointegration and Granger causality tests were used to examine semi-strong form efficiency. Semi-strong form efficiency was not supported as these tests indicated a high degree of interdependence among the South Asian stock markets.

Kuntara and Lee [18] analysed the "Weak-Form Efficiency in Currency Markets" and found that the currencies trend and technical trading rules produced statistically and economically significant profits resulting in weak form foreign exchange market inefficiency. The study used a new database of currency futures for 1975-2006 that included old and newly liquid currencies. The findings from the recent data are contradictory. The profitability of trend following eroded for major currencies and their associated cross exchange rates around the mid-1990s. Newly liquid currencies after 2000 do trend, however, just as major currencies did in earlier years. The evidence is consistent with early weak-form inefficiency followed by vanishing trends as traders learn and adapt their strate- 
gies.

Ibrahim et al. [19] investigated the weak-form efficiency of the foreign exchange market in thirty (30) Organization for Economic Cooperation and Development (OECD) countries. They employed Augmented Dickey-Fuller (ADF), Philip-Perron (PP) and Kwiatkowski-Phillips-Schmidt-Shin analysis to examine for the unit root. Using weekly data for the period 2000 to 2007, the results for weak-form efficiency using ADF and PP tests indicated that the exchange rates studied followed random walks. The current value of the exchange rate cannot be predicted using its past values and was consistent with the theory of EMH.

[7] examined the weak and semi-strong form efficiency of four of the seven foreign exchange markets of South Asia; namely, Pakistan, India, Sri Lanka and Bangladesh; using three bilateral foreign exchange rates-USD, GBP and JPY for a period of 5 years starting January 1995 to December 2010. Results indicated that all four foreign exchange markets were consistent with the weak-form of the Efficient Market Hypothesis. However, the results provided evidence against the semi-strong version of the Efficient Market hypothesis.

Dinica et al. [20] analyzed the efficiency of EUR/USD market through the application of a trading system. They used a genetic algorithm based on technical analysis indicators such as Exponential Moving Average (EMA), Moving Average Convergence Divergence (MACD), Relative Strength Index (RSI) and Filter that provided buying and selling recommendations to investors. Results indicated inconsistency in finding a set of trading rules. Strategies that achieve very good returns in the training period showed difficulty in returning positive results in the testing period, this being consistent with the efficient market hypothesis (EMH).

Sing and Sapna [21] examined the weak form market efficiency in five stock exchanges of Asian countries. The data used consisted of daily, weekly and monthly closing values. The results of the run test stated that the Bombay stock exchange (BSE) and Singapore stock exchange (STI) do not follow random behaviour in case of daily prices. In case of monthly price, BSE has been found weak form efficient. Further, the results of autocorrelation and Ljung-Box test revealed that all stock exchanges under study follow random walk behaviour in case of monthly and weekly prices except BSE.

[12] examined the efficiency of the Mauritian Foreign Exchange market by using daily observations for USD for the period July 2001 to July 2014. The randomness of the Mauritian Foreign Exchange market were tested by employing the parametric test-Augmented Dickey-Fuller unit root tests and the nonparametric tests-Phillips-Peron unit root test and Kwiatkowski-Phillips-SchmidtShin. The unit root tests revealed that the Mauritian foreign exchange market was weakly efficient indicating that the values for earlier period could not be used to forecast the present values of the exchange rate.

[22] analyzed the efficiency of foreign exchange market using Random Walk Models. For the efficient market hypothesis, daily rates of USDCHF currency pairs for 5 years period from 01/01/2009 to 31/12/2013 were taken. Results 
showed that the foreign exchange market was not a weak form efficient in respect of this currency pair, and traders of foreign exchange in respect of these current pair was able to predict their future values based on their values in the recent past

Sheefeeni et al. [23] investigated the weak form efficiency of the foreign exchange market in Namibia using three bilateral exchange rates. Weak-form efficiency is examined using the traditional unit root tests, the Augmented Dickey Fuller, Phillips Perron and Kwiatkowski-Phillips-Schmidt-Shin. The study applied these test on the monthly data for the period covering the year 1993 to 2011. The results showed that there exists weak form efficiency in Namibia's foreign exchange market suggesting that the past values cannot be used to predict the current values. The weak-form efficiency on the Namibia stock market is attributable to its correlation with the JSE which was also found to be weak form efficient for the period investigated.

Makorvsky [24] examined the efficiency hypothesis of FOREX market in the sample of panel dataset of the Central European countries by using the regression analysis, time series analysis, vector autoregression or linear co-integration. They tested also the influence of the risk premium, the influence of transaction costs and its response to equilibrium readjustment. Results indicated that there was a strong tendency of nominal convergence in EU countries.

Mabakeng et al. [25] analysed the semi-strong form efficiency of the foreign exchange market in Namibia using three bilateral exchange rates. The semi-strong form efficiency was examined using the cointegration test and Granger causality test. The study applied these tests on the monthly nominal spot exchange rate data for the period between the years 1993 and 2011. The results from the study indicated that semi-strong form efficiency was evident within Namibia's foreign exchange market. This suggested that historical data could not be used to predict current and future market prices.

Cicek [26] examined the within-country market efficiency of the Turkish foreign exchange markets on the basis of the forward rate unbiasedness hypothesis, in case of the Turkish lira/US dollar and the Turkish lira/Euro for the period February 5, 2005 through July 26, 2013 by Johansen cointegration method. Unit root test results supported the market efficiency in its weak-form. However, the existence of cointegration between the forward rates and its corresponding future spot rates with a unitary cointegrating vector and there exists no systematic expectation errors provide evidence for forward rate unbiasedness hypothesis and thus against market efficiency in semi-strong form.

Kumar et al. [27] examined the presence of weak form of market efficiency, non-linearity and chaotic behaviour in the foreign exchange markets of Brazil, Russia, India, China and South Africa using various tests. Monthly Nominal Effective Exchange Rate (NEER) data for the said countries, ranging from April 1994 to September 2014 were examined. The analysis was carried out using variance ratio (VR) tests, BDS test, Hinich Bispectrum test, Teräsvirta Neural Network test and estimation of Largest Lyapunov exponents (LLE's). The first 
stage consisted of testing for weak-form market efficiency using VR tests, which rejected the Weak-form Efficient Market Hypothesis for all the five series. The next step was to analyze the possible presence of non-linearity, and this was carried out using BDS test, Hinich Bispectrum test, and Teräsvirta Neural Network test. The tests confirmed the presence of non-linearity in the five series under study. The last step of the study was to analyze the structure of nonlinearity. LLE's were estimated for all series in order to examine the possible presence of chaos. LLE's for all the 5 series returned positive values, and confirmed the presence of an underlying chaotic structure for all markets.

\section{Research Methodology}

In order to determine the existence of weak-form and semi-strong form market efficiency in the Mauritian foreign market, this paper will use the AugmentedDickey Fuller Test and Philips Peron Test to test the weak form market efficiency to determine if spot exchange rates in Mauritius behave as random walk patterns. Secondly, Johansen Cointegration Test, Granger Causality Test and Variance Decomposition is used to determine the existence of strong-form market efficiency by investigating the cointegrating relationship and non-existence of causal relationship among the spot exchange rates as adapted by [7] [8] [19] and [25].

\subsection{Data Sample and Data Measurement}

The data sample in this study is made up of 5 set of official spot exchange rates namely EUR/MUR, USD/MUR, GBP/MUR and JPY/ MUR. All the data is secondary and are collected from the Mauritius Commercial Bank website [28]. The data consists of 1247 daily observations on official spot exchange rates ranging from January 2012 to December 2016. The nominal spot exchange rates were analysed by using the natural logarithm of these data.

\subsection{Research Hypotheses}

As the objective is to investigate the efficiency of foreign exchange market in Mauritius, the following hypotheses for testing have been designed as follows:

Part 1: Weak-Form Market Hypothesis: Augmented Dickey Fuller Test, Philips Peron Test

$\mathrm{H}_{1}$-Unit Root exists in Mauritian FX time series (follows a random walk)

$\mathrm{H}_{2}$-Unit Root does not exist in Mauritian FX time series (does not follow a random walk)

Part 2: Semi-Strong Form Market Hypothesis:

Granger Causality Test and Variance Decomposition

$\mathrm{H}_{1}$-Granger causality does not exist in Mauritian FX time series

$\mathrm{H}_{2}$-Granger causality exists in Mauritian FX time series

\subsection{Econometric Measurement}

Exchange rates, in common with many financial variables, typically exhibit 
non-stationary time series processes: that is, they are series trending over time, rather than mean-reverting or stationary series Aron [15]. Here, two unit roots test are used to determine if the spot exchange series follow a random walk. Spot exchange rate series follow a random walk if the foreign exchange data reflect all available information. If the unit root tests indicate that the forex series are non-stationary, then they are said to follow a random walk process.

\subsubsection{Augmented-Dickey Fuller Test}

The ADF test was developed by Dickey and Fuller in 1984 which is an augmented version of the DF test. The augmented Dickey-Fuller (ADF) statistic, used in the test, should be a negative number. The more negative it is, the stronger the rejection of the hypothesis that there is a unit root at some level of confidence. It is also important that the error term should be correlated.

The ADF test is indicated as follows:-

$$
\Delta x_{t}=a_{0}+b_{0} x_{t-1}+\Sigma c_{0} \Delta x_{t-1}+w_{t}
$$

where

$\Delta$ is the difference operator, $a_{0}, b_{0}, c_{0}$ are coefficients to be estimated,

$x$ is a variable whose unit roots are examined and $\mathrm{w}$ is the error term.

The null hypothesis for this is $b_{0}=0$ (i.e. the series is non-stationary and a random walk with drift) against the alternative hypothesis $b_{0}<0$ (i.e. the series is stationary).

Most time series in economics exhibit trend over time and when this is the case, it is usually said that these time series are not stationary (contain unit root). Being non-stationary implies that the mean, variance and covariance are not constant over time. In the context of this study, when data contains a unit root it means the data follows a random walk

\subsubsection{Philips Peron Test}

The Phillips-Perron test [29] is a unit root test which is used in time series analysis to test the null hypothesis that a time series is integrated of order 1. It makes a non-parametric correction to the $t$-test stastistic with $Z t$ stastistic allowing for autocorrelation and heteroscedasticity in the disturbance process of the test equation. The regression equation of the PP test is indicated as follows:

$$
\gamma_{i}=\alpha+p y_{t-1}+\epsilon_{t}
$$

where

$$
\begin{aligned}
& y \text { and } p \text { are parameters } \\
& \epsilon \text { is referred to as white noise } \\
& t \text { is the transcript for time. }
\end{aligned}
$$

\subsection{Semi-Strong Form Market Efficiency}

This study will use three econometric measures to test the semi-strong form of the EMH namely Johansen Cointegration Test, Granger Causality Test and Variance Decomposition Test. 


\subsection{Johansen Cointegration Test}

Cointegration tests are carried out in order to see if the markets share a long run stochastic trend. The first step in the analysis tests for the order of integration of the variables. Order of integration refers to the number of times a variable is differenced before becoming stationary. One condition for the co-integration tests is that the variables in the co-integrating equation must be integrated of the same order. In this paper, ADF and PP tests are used to test the stationarity of the residuals obtained from the bivariate cointegration equations.

Johansen's co-integration is based on the following vector auto regression equation:

$$
y_{t}=A_{t} y_{t-1}+\cdots+A_{t} y_{t-p}+\beta x_{t}+\varepsilon_{t}
$$

where:-

$y_{t}$ is a k-vector of non-stationary $\mathrm{I}(1)$ variables,

$x_{t}$ is a vector of deterministic variables

$\varepsilon_{t}$ is a vector of innovations

In making inferences about the number of cointegrating relations, two statistics known as trace statistic and maximal eigenvalue statistic are used. The trace statistic analysed the null hypothesis that there are at most $r$ cointegrating vectors against the alternative hypothesis of $r$ or more cointegrating vectors. Meanwhile, in the maximal eigenvalue statistic test the null hypothesis of $r$ cointegrating vectors is tested against the alternative of $r+1$ cointegrating vectors [8]. To make inferences regarding the number of cointegrating relationships, trace and maximum eigenvalue statistics are compared with the critical values tabulated in Osterwald-Lenum (1992).

The vector error correction (VEC) is also estimated to investigate weak exogeneity and to do hypothesis testing since VEC is applied only if there is a long run cointegrated relationship among the series. To be able to run Johansen cointegrating test the data must be nonstationary. If there is no long run cointegrated relationship among the variables, a VAR model specification is estimated.

\subsection{Granger Causality Test}

Granger Causality TestBrooks [30] [31] is an additional test to verify the results of the cointegration test by confirming the presence of the semi-strong form of EMH whereby there should be no causal relationships between the currencies indicating that one exchange rate can be forecasted by one or more of the other exchange rates.

The Granger causality test is useful in finding whether one time-series $\left(x_{t}\right)$ can be predicted by another time-series $\left(y_{t}\right)$. The test is carried out by regressing $x_{t}$ on its lagged values and the lagged values of $y_{t}$ If the results indicate that $x_{t}$ can be predicted by $y_{p}$ it is said that $y_{t}$ Granger causes $x_{t}$. However, the

Granger causality implies a correlation between the current value of one variable and the past values of others; it does not mean changes in one variable cause changes in another. If there are two series $Y_{t} \& X_{t}$ then it is said that $X_{t}$ doesn't 
granger cause $Y_{t}$ if all lagged coefficients for $X_{t}$ are zero, that is:

$$
Y_{t}=\alpha_{0}+\alpha_{1} Y_{t-1}+\cdots+\beta_{1} X_{t-1}+\cdots+\beta_{p} X_{t-p}+\epsilon_{t}
$$

Then, $\beta_{1}=\beta_{2}=\cdots=\beta_{p}=0$ that is lagged of Xt has no effect on $Y_{t}$.

Note that model selection criteria, such as the Bayesian Information Criterion (BIC, Schwartz (1978)) or the Akaike Information Criterion (AIC, Akaike (1974)), can be used to determine the appropriate model order $p$.

\subsection{Variance Decomposition Analysis}

Variance Decomposition indicate the proportion of the movements in the dependent variables that are due to their "own" shocks, versus shocks to the other variables [31]. It is utilized to determine the causality beyond the sample period. In this study, the variance of the forecast error of a particular variable is divided into proportions creditable to shocks or innovations in each variable in the system as well as its own [7].

A shock to the ith variable will directly affect that variable of course, but it will also be transmitted to all of the other variables in the system through the dynamic structure of the VAR. Variance decompositions determine how much of the s-step-ahead forecast error variance of a given variable is explained by innovations to each explanatory variable for $s=1,2, \cdots[31]$.

\section{Results}

\subsection{Descriptive Statistics}

We started our investigation with some basic descriptive statistics of the foreign exchange data for Mauritius focusing on the mean, standard deviation as a measure of volatility, skewness and kurtosis. The descriptive statistics are represented in Table 1 below.

Table 1. Descriptive statistics.

\begin{tabular}{ccccc}
\hline & EUR_MUR & GBP_MUR & USD_MUR & JPY_MUR \\
\hline Mean & 1.5912 & 1.6875 & 1.5025 & 1.4931 \\
Median & 1.5922 & 1.6865 & 1.4846 & 1.4815 \\
Maximum & 1.6144 & 1.7398 & 1.5545 & 1.5888 \\
Minimum & 1.5560 & 1.6309 & 1.4493 & 1.4049 \\
Std. Dev & 0.0136 & 0.0261 & 0.0344 & 0.0453 \\
Skewness & -0.3588 & 0.1989 & 0.3284 & 0.5366 \\
Kurtosis & 2.3003 & 2.3286 & 1.4424 & 2.2680 \\
Jarque-Bera & 52.1983 & 31.6445 & 148.4635 & 87.6912 \\
Probalility & 0.0000 & 0.0000 & 0.0000 & 0.0000 \\
Observations & 1247 & 1247 & 1247 & 1247 \\
\hline
\end{tabular}


Table 1 shows the descriptive statistics of the Mauritian foreign exchange market based on 1247 observations namely EUR, GBP, USD and JPY respectively. According to this study, it indicates that all variables have a positive mean with a positive kurtosis which states that the distribution of the foreign exchange data are leptokurtic resulting in higher peaks than expected from normal distribution. Moreover, it is seen that some foreign exchange series are skewed to the right namely (GBP (0.1989), USD (0.3284) and JPY (0.5366) resulting in a rise in returns while EUR $(-0.3588)$ is skewed to the left resulting in a fall in returns. Moreover, the standard deviation reports that the FX market is very low representing a very low volatility in returns.

\subsection{Empirical Results on Weak Form Market Hypothesis}

In this paper, the Augmented Dickey-Fuller (ADF) and Phillips-Perron (PP) were used to examine for the unit root. Here, the unit root tests are conducted at level and first difference.

Table 2 reports the results of the ADF unit root test for the four spot exchange rates for levels and the first differences of the natural log values for both "Intercept" and "Intercept with trend". At first point, all exchange data are non-stationary in their levels but when they are first differenced, they become stationary. Both the results for ADF test statistic value (Intercept) of EUR/MUR -37.3551, GBP/MUR -10.6374, USD/MUR -12.08791 and JPY/MUR -10.27241 and the ADF results for "Intercept with trend" of EUR/MUR -10.92158, GBP/MUR - 10.80607, USD/MUR - 12.08343 and JPY/MUR - 10.32014. The results are significant at $1 \%$ level. In other words, the results are conformed with the weak form efficient hypothesis. Hence, the Mauritian Foreign exchange market is efficient in the weak form whereby exchange rates at $t-1$ cannot be used to predict future exchange rates at time $t$. Therefore, the participants in the foreign exchange market in Mauritius cannot devise any statistical technique to gain from foreign exchange market transactions.

Table 2. ADF Test results for unit roots.

\begin{tabular}{cccccccccc}
\hline & \multicolumn{3}{c}{ Level } & & \multicolumn{4}{c}{ First Differences } \\
\hline Currency & Intercept & LAG & $\begin{array}{c}\text { Intercept } \\
\text { \& Trend }\end{array}$ & LAG & Intercept & LAG & $\begin{array}{c}\text { Intercept } \\
\text { \& Trend }\end{array}$ & LAG \\
\hline EURO & -2.3816 & 1 & -2.4079 & 1 & $-37.3551^{*}$ & 0 & $-10.92158^{*}$ & 15 \\
GBP & -1.3743 & 12 & -2.3051 & 12 & $-10.6374^{*}$ & 11 & $-10.80607^{*}$ & 11 \\
USD & -0.8640 & 4 & -1.7783 & 4 & $-12.08791^{*}$ & 3 & $-12.08343^{*}$ & 3 \\
JPY & -0.7595 & 10 & -1.2844 & 10 & $-10.27241^{*}$ & 8 & $-10.32014^{*}$ & 8 \\
(Author's Computation) & & & & & & & & \\
\hline
\end{tabular}

Notes for the above table: ${ }^{\star}$ denotes significance at $1 \%$ level; Mackinnon (1996) one-sided $p$-values. 


\subsection{Testing for Unit Root Using Phillip Perron Test}

Table 3 examines the results of the PP unit root test for the four spot exchange rates for levels and the first differences of the natural log values. Here, it is seen that the results are similar to the ADF test statistics where at first point, all exchange data are non-stationary at the first level. On the other hand, when tested at the first difference, they become stationary. The PP test statistic value of both “Intercept"-EUR/MUR -37.46186, GBP/MUR -34.47336, USD/MUR -28.77068 and JPY/MUR -34.54471 and "Intercept with trend" EUR/MUR -37.50921, GBP/MUR -34.56479, USD/MUR -28.76248 and JPY/MUR -34.57147 are statistically significant at $1 \%$ level. Therefore, the null hypothesis that Mauritian foreign series are non-stationary will have to be rejected and the other alternative will have to be accepted. Hence, we can say that the foreign exchange data series are stationary and do not have a unit root. The results affirm the earlier results of the ADF test stating that the foreign exchange rates in Mauritius behave as random walks providing support for the weak-form of the EMH.

According to the study, both tests confirm that the data become non-stationary at first level and become stationary when they are tested at the First difference which support the existence of the weak form efficiency. In other words, the Mauritian foreign exchange market is efficient in the weak form. The results of the study are consistent with a number of studies ${ }^{1}$.

\subsection{Empirical Results on Semi-Strong Form Market Hypothesis}

Table 4 reports the Johansen co-integration test results carried out to test for long-run co-movement among the four currencies. The co-integrating properties are analyzed using two test statistics, trace and maximum Eigen value. The values of trace statistics are given in column two, with five and one percent

Table 3. PP test results for unit roots

\begin{tabular}{ccccccccc}
\hline & \multicolumn{2}{c}{ Level } & & \multicolumn{3}{c}{ First Differences } \\
Currency & Intercept & LAG & $\begin{array}{c}\text { Intercept } \\
\text { \& Trend }\end{array}$ & LAG & Intercept & LAG & $\begin{array}{c}\text { Intercept } \\
\text { \& Trend }\end{array}$ & LAG \\
\hline EURO & -2.2584 & 8 & -2.3435 & 9 & $-37.46186^{*}$ & 11 & $-37.50921^{*}$ & 11 \\
GBP & -1.6873 & 6 & -2.5881 & 8 & $-34.47336^{*}$ & 8 & $-34.56479^{*}$ & 10 \\
USD & -0.8796 & 20 & -1.7004 & 20 & $-28.77068^{*}$ & 17 & $-28.76248^{*}$ & 17 \\
JPY & -0.4059 & 6 & -1.0434 & 6 & $-34.54471^{*}$ & 5 & $-34.57147^{*}$ & 5 \\
(Author's Computation) & & & & & & & & \\
\hline
\end{tabular}

Notes for the above table: ${ }^{\star}$ denotes significance at $1 \%$ level; Mackinnon (1996) one-sided $p$-values.

${ }^{1}$ See Kisto et al. [12], Sheefeeni et al. [23], Wickremasinghe [8], Ibrahim et al. [14], Chaudhery [7], Mabakeng [25] among others but inconsistent with Aroskar [16], Kuntara and Lee [18] and Krishnaveni et al. [22]. 
Table 4. Johansen cointegration test results.

\begin{tabular}{ccccccc}
\hline $\begin{array}{c}\text { Null } \\
\text { Hypothesis }\end{array}$ & $\begin{array}{c}\text { Trace } \\
\text { Statistics }\end{array}$ & $\begin{array}{c}5 \% \text { Critical } \\
\text { Value }\end{array}$ & $\begin{array}{c}\text { 1\% Critical } \\
\text { Value }\end{array}$ & $\begin{array}{c}\text { Maximum } \\
\text { Eigen Value } \\
\text { Statistics }\end{array}$ & $\begin{array}{c}\text { 5\% Critical } \\
\text { Value }\end{array}$ & $\begin{array}{c}\text { 1\% Critical } \\
\text { Value }\end{array}$ \\
\hline $\mathbf{r}=\mathbf{0}$ & 38.658 & 47.21 & 54.46 & 22.010 & 27.07 & 32.24 \\
$\mathbf{r}<1$ & 16.648 & 29.68 & 35.65 & 10.293 & 20.97 & 25.52 \\
$\mathbf{r}<\mathbf{2}$ & 6.355 & 15.41 & 20.04 & 6.297 & 14.07 & 18.63 \\
$\mathbf{r}<3$ & 0.058 & 3.76 & 6.65 & 0.058 & 3.76 & 6.65 \\
& & & (Author's Calculation) & & \\
\hline
\end{tabular}

Notes for the above table: 1) EURO, GBP, USD and JPY denote the nominal exchange rates for EURO, British Pound, US Dollar and Japanese Yen respectively. 2) a and b imply significance at the $1 \%$ and $5 \%$ level, respectively. 3) Lag lengths in Vector Autogression were selected using Likelihood Ratio Test. 4) Critical Values for the Trace and Maximal Eigen Value Test are obtained from Osterwald Lenum (1992).

critical values in columns three and four, respectively. Similarly, the values of maximum Eigen value are shown in column five, with five and one percent critical values in columns six and seven, respectively.

According to the study, the result shows that around $100 \%$ of the exchange rate pairs are not cointegrated. Therefore, there is no long run relationship among the exchange rate variables. As a result, we can say that the Mauritian foreign exchange market is efficient in the semi-strong form which is consistent with the study a number of studies².

However, the results are still not conclusive. Therefore, to further verify and confirm the presence of any relationship between the variables, we proceed to carry out the Granger Causality test. The results of which are tabulated Table 5.

Based on the given results, it is seen that there are unidirectional causal relationships between the various foreign exchange data namely GBP to EUR, GBP to USD, GBP to JPY and USD to JPY. All the results are statistically significant at $1 \%$ respectively. However, there is one bidirectional causal relationships namely USD to EUR and vice-versa. Therefore, the null hypothesis that there is no granger causality relationship among the Mauritian foreign exchange market will have to be rejected. The results conquer with a number of findings ${ }^{3}$.

The basic requirement of the semi-strong form market efficiency is that there should be no granger causality relationships among the foreign exchange data. However, the empirical results clearly indicate the presence of causal relationships which states that one exchange rate can predict one or more exchange rates which is contradictory to the semi-strong form market efficiency. Therefore, it can be deduced that the Mauritian foreign market is not efficient in a semistrong form. However, another test that is Variance Decomposition will have to be further performed to confirm the results of Granger Causality test.

${ }^{2}$ See Wickremasinghe [8], Chaudhery [7], Mabakeng [25] among others.

${ }^{3}$ See Chaudhery [7], Mabakeng [25], Wickremasinghe [8] among others but inconsistent with Cooray and Wickremasinghe [17] and Cicek [26]. 
Table 5. Granger causality test results

\begin{tabular}{lcc}
\hline \multicolumn{1}{c}{ Null Hypothesis } & F-Statistics & Probality \\
\hline GBP_MUR does not Granger Cause EUR_MUR & 15.7862 & $0.00^{*}$ \\
EUR_MUR does not Granger Cause GBP_MUR & 1.28634 & 0.2534 \\
USD_MUR does not Granger Cause EUR_MUR & 74.6328 & $0.00^{*}$ \\
EUR_MUR does not Granger Cause USD_MUR & 3.7302 & $0.0005^{*}$ \\
JPY_MUR does not Granger Cause EUR_MUR & 1.29828 & 0.2475 \\
EUR_MUR does not Granger Cause JPY_MUR & 0.83613 & 0.5573 \\
USD_MUR does not Granger Cause GBP_MUR & 1.30408 & 0.2446 \\
GBP_MUR does not Granger Cause USD_MUR & 9.0612 & $0.00^{*}$ \\
JPY_MUR does not Granger Cause GBP_MUR & 1.262 & 0.2658 \\
GBP_MUR does not Granger Cause JPY_MUR & 5.73899 & $0.00^{*}$ \\
JPY_MUR does not Granger Cause USD_MUR & 1.59979 & 0.1314 \\
USD_MUR does not Granger Cause JPY_MUR & 2.94586 & $0.0046^{*}$ \\
(Author’s Computation) & & \\
\hline
\end{tabular}

Notes for the above table: 1) EUR, USD, GBP and JPY denote the spot exchange rates for Euro, US dollar, British Pound and Japanese yen and US dollar respectively. 2) ${ }^{*}$ and ${ }^{* *}$ implies significance at $1 \%$ and $5 \%$ respectively. 3) Implies the rejection of the null hypothesis. 4) Seven lags included in the vector auto regressions are determined using the Likelihood (LR) test.

\subsection{Variance Decomposition}

Table 6 represents the results of the variance decomposition analysis. This analysis was used to confirm the Granger causality test results to examine the causality of Mauritian foreign exchange data. The data results stated the explanation how much of a spot exchange rate's own shock is explained by movements in its own variance and those of the others over the forecast horizon (i.e. 48 months). The order of the spot exchange rates used in the analysis was as follows Euro (EUR), Pound Sterling (GBP), US Dollar (USD) Japanese yen (JPY).

According to the results reported in Table 6, Euro and the British Pound explain up to $100 \%$ and $99.78 \%$ of their respective variances even after 48 months following the once-only shock that is GBP $96.88 \%$ and Euro $95.02 \%$. However, the shocks concerning USD and JPY range between $90.32 \%$ and $85.35 \%$ respectively. The other exchange rates explain a very little proportion of the variability of these two exchange rates at all time horizons considered.

When the GBP exchange rate is considered, most of its variance is explained by itself. About $99.78 \%$ of the variability of the GBP exchange rate in the first month is explained by itself. At this time horizon, EUR exchange rate explains most of the remaining variability (around $0.22 \%$ ) of the GBP exchange rate. The higher the time horizon, the more is the variability of the GBP explained by the EURO and US dollar exchange rate. At longer time period that is 48 months, USD and the EUR account $1.22 \%$ and $0.82 \%$ respectively of the variability of the GBP exchange rate. 
Table 6. Variance decomposition test results.

\begin{tabular}{|c|c|c|c|c|}
\hline \multirow{2}{*}{$\begin{array}{c}\text { Period } \\
\text { Relative Variance }\end{array}$} & \multicolumn{4}{|c|}{ Percentage of Forecast Variance Explained by shocks in } \\
\hline & EUR & GBP & USD & JPY \\
\hline 1 & 100.00 & 0.00 & 0.00 & 0.00 \\
\hline 12 & 97.52 & 0.83 & 1.30 & 0.35 \\
\hline EUR & 97.04 & 0.66 & 1.25 & 1.04 \\
\hline 36 & 96.23 & 0.54 & 1.13 & 2.10 \\
\hline 48 & 95.02 & 0.46 & 1.02 & 3.50 \\
\hline 1 & 0.22 & 99.78 & 0.00 & 0.00 \\
\hline 12 & 0.56 & 99.21 & 0.23 & 0.00 \\
\hline GBP & 0.90 & 98.61 & 0.48 & 0.01 \\
\hline 36 & 1.32 & 97.83 & 0.81 & 0.04 \\
\hline 48 & 0.82 & 96.88 & 1.22 & 0.08 \\
\hline 1 & 0.01 & 1.27 & 98.71 & 0.00 \\
\hline 12 & 2.57 & 0.84 & 96.51 & 0.02 \\
\hline USD & 6.06 & 0.79 & 93.07 & 0.08 \\
\hline 36 & 10.00 & 0.67 & 89.19 & 0.14 \\
\hline 48 & 13.93 & 0.54 & 85.35 & 0.17 \\
\hline 1 & 1.83 & 0.04 & 0.01 & 98.13 \\
\hline 12 & 3.03 & 1.63 & 0.89 & 94.45 \\
\hline JPY & 3.26 & 2.77 & 0.87 & 93.10 \\
\hline 36 & 3.37 & 4.11 & 0.78 & 91.74 \\
\hline 48 & 3.40 & 5.60 & 0.68 & 90.32 \\
\hline
\end{tabular}

Notes: 1) Variance decompositions for the months 1, 12, 24, 36, and 48 only are reported. All figures have been rounded to two decimal places. 2) EUR, GBP, USD and JPY denote the nominal exchange rates for Euro, British Pound, US Dollar and Japanese yen. 3) Figures in column 1 refer to months after a once-only shock. Cholesky ordering for the variance decomposition was $\log (\mathrm{EUR}), \log (\mathrm{GBP}), \log (\mathrm{USD})$ and $\log (\mathrm{JPY})$.

Regarding USD exchange rate, $98.13 \%$ of its variance is explained by itself. At this same period, GBP accounts for $1.27 \%$. However, the influence of the EUR is more prominent at all time horizons. When compared to the influence of the US dollar and the EURO at long time horizons which are $85.35 \%$ and $13.93 \%$ respectively, the impact on GBP and Japanese yen on Mauritian rupee is not so prominent at longer time horizons.

As far as JPY exchange rate is concerned, it seems that the variance is explained by $98.13 \%$ by itself in the first month. Moreover, EUR explains most of remaining variability that is $1.83 \%$ of the JPY exchange rate. At longer time horizons that is 48 months, JPY stands for $90.32 \%$ by itself and GBP exchange rate seems to be the most prominent exchange rate (5.60\%) followed by the EUR exchange rate (3.40\%). However, USD explains a very low influence on JPY that is $0.68 \%$ respectively. 
The above results stated that the variance of one exchange rate is explained by others revealing causal relationships between currencies. Hence, these results do not support the semi-strong form of the EMH to the Mauritian foreign exchange market. Such causal relationships can be used to predict the future value of one currency from the past values of one or more of the other currencies.

In this study, it has been noted that the results of the Johansen cointegration test state that there is no co-integration relationship among the foreign exchange variables. However, the Granger Causality Test and variance decomposition analysis confirm the contrary and therefore indicate that the movement in one or more of the currencies can be predicted using the other exchange rates. These results are inconsistent with the efficient market hypothesis in its semi-strong form. Hence, the results conquer with a number of studies ${ }^{4}$.

\section{Conclusions}

The foreign exchange market is one of the main important financial aspect of any economy of a country. The study was concerned with the investigation of the efficiency of the Mauritian foreign exchange market based on the theory of the EMH concentrating on the weak form and semi-strong market hypothesis. The study used daily spot rates data for a period of 5 years ranging from 2012 and 2016 with a total number of 1247 observations.

Firstly, the empirical results indicated that the Augmented Dicker Fuller and Phillips Perron unit root test conclude that the foreign exchange market is efficient in the weak-form market hypothesis. Therefore, the results are strictly consistent with the number of studies ${ }^{5}$.

Moreover, the Johansen cointegration test was also examined and confirmed that there were no long-run relationships among the foreign exchange variables. However, when the Granger causality test was performed, it stated that there was the presence of unidirectional and bidirectional causal relationships between the various spot rates tested. Variance Decomposition analysis was also utilized to confirm the existence of long run comovements among the variables and concluded that there was the presence of innovations and shocks in the long run among the foreign exchange data. The findings conquer with the number of studies ${ }^{6}$.

Based on the given results, it is concluded that the foreign exchange market in Mauritius is efficient in the weak form. These results indicate that the participants in the foreign exchange market in Mauritius cannot sub-divide some rule or technique that can be utilized to forecast future movements of an exchange rate from its past values.

\footnotetext{
${ }^{4}$ See Chaudhery [7], Wickremasinghe [8], Mabakeng [25] among others but inconsistent with Cicek [26] and Cooray and Wickremasinghe [17].

${ }^{5}$ See Kisto et al. [12], Mabakeng [25], Chaudhery [7], Ibrahim et al. [19], Wickremasinghe [8] among others but inconsistent with Aron [15], Aroskar [16], Kuntara and Lee [18] and Krishnaveni et al [22].

${ }^{6}$ See Chaudhery (2012), Wickremasinghe (2004), Mabakeng (2015) but inconsistent with Cooray and Wickremasinghe (2007) and Cicek (2014).
} 
However, when the Johansen Cointegration test is performed, the semistrong form efficiency was supported but when the Granger Causality test and Variance Decomposition were used, the results showed that there were long run relationships among the various foreign exchange rates which is not in accordance with the semi-strong form. In other words, one exchange rate can predict one or more exchange rates and that exchange rate traders and market players can make returns on speculation through public information.

The results of the present research have important implications for the Mauritian government policy-making institutions as well as for the participants of the foreign exchange markets. The government will have to take action so as to reduce the exchange rate volatility and instability and appraise the effects of different economic policies on the behaviour of exchange rates. The participants of the foreign exchange market can benefit by devising trading rules or strategies to make profits from transactions in the foreign exchange market.

\section{References}

[1] Le Baron, B. (1999) Technical Trading Rule Profitability and Foreign Exchange Intervention. Journal of International Economics, 49, 125-143. https://doi.org/10.1016/S0022-1996(98)00061-0

[2] Amma, T. (2011) Capital Market Efficiency: Evidence from Pakistan. Interdisciplinary Journal of Contemporary Research in Business, 3, 8.

[3] Fama, E. (1970) Efficient Capital Market: A Review of Theory and Empirical Work. Journal of Finance, 25, 382-417. https://doi.org/10.2307/2325486

[4] Fama, E.F. (1991) Efficient Capital Markets: II. The Journal of Finance, 46, 1575-1617. https://doi.org/10.1111/j.1540-6261.1991.tb04636.x

[5] Fama, E. (1984) Forward and Spot Exchange Rates. Journal of Monetary Economics, 14, 319-338. https://doi.org/10.1016/0304-3932(84)90046-1

[6] Bashir, R., Shakir, S., Badar, A. and Hassan, A. (2014) The Efficiency of Foreign Exchange Markets in Pakistan: An Empirical Analysis. The Lahore Journal of Economics, 19, 133-149.

[7] Arif, C.S., et al. (2012) Efficiency of the Foreign Exchange Markets of South Asian Countries. PIDE Working Papers.

[8] Wickremasinghe, B.G. (2004) Efficiency of Foreign Exchange Markets: A Developing Country Perspective, ABERU Discussion Paper 3, 2004.

[9] Hamid, K., Suleman, M.T., Shah, S.Z.A. and Akash, R.S.I. (2010) Testing the Weak form of Efficient Market Hypothesis: Empirical Evidence from Asia-Pacific Markets. International Research Journal of Finance and Economics, 58.

[10] Fowdar, S., Subadar, U.A., Lamport, M., Sunassee, R.V. and Fawzee, S. (2007) Assessing the Level of Efficiency of the Stock Exchange of Mauritius. UoM Research Journal - Special Issue, 13A, 90.

[11] Fauzel, S. (2016) A Generalized Autoregressive Conditional Heteroscedastic Approach for the Assessment of Weak-Form-Efficiency and Seasonality Effect: Evidence from Mauritius. International Journal of Economics and Financial Issues, 6 , 745-755.

[12] Kisto, M. and Ummersingh, S. (2014) Efficiency of the Foreign Exchange Market in 
Mauritius. Research Journal of Science and IT Management, 4, 47.

[13] Hakio, C. (1981) Expectations and the Forward Exchange Rate. International Economic Review, 22, 663-678. https://doi.org/10.2307/2526167

[14] Coleman, M. (1990) Cointegration-Based Tests of Daily Foreign Exchange Market Efficiency. Economics Letters, 32, 53-59. https://doi.org/10.1016/0165-1765(90)90049-7

[15] Aron, J. (1997) Foreign Exchange Market Efficiency Tests in South Africa. Centre for the Study of African Economies, Department of Economics, University of Oxford, Oxford.

[16] Aroskar, R., Sarkar, S.K. and Peggy, E.S. (2004) European Foreign Exchange Market Efficiency: Evidence Based on Crisis and Non-Crisis Periods. International Review of Financial Analysis, 13, 333-347. https://doi.org/10.1016/j.irfa.2004.02.011

[17] Cooray, A. and Wrickremasinghe, G. (2007) The Efficiency of Emerging Stock Markets: Empirical Evidence from the South Asian Region. University of Wollongong.

[18] Pukthuanthong-Le, K. and Thomas III, L.R. (2008) Weak-Form Efficiency in Currency Markets. Financial Analysts Journal, 3, 31-52. https://doi.org/10.2469/faj.v64.n3.5

[19] Ibrahim, J., Ghani, H.A. and Salleh, S.I.M. (2011) Weak Form of Foreign Exchange Market in the Organisation for Economic Cooperation and Development Countries: Unit Root Test. International Journal of Business and Management, 6, 55. https://doi.org/10.5539/ijbm.v6n6p55

[20] Boboc, I.-A. and Dinică, M.-C. (2013) An Algorithm to Test the Efficient Market Hypothesis. PLoS ONE, 8, e78177. https://doi.org/10.1371/journal.pone.0078177

[21] Sing, S. and Sapna, K. (2013) Weak Form Efficiency of Selected Asian Stock Exchange. International Journal of $360^{\circ}$ Management Review, 1-17.

[22] Krishnaveni, P. and Varadaraj, S. (2014) An Experimental Study on Currency Market Efficiency USDCHF Currency Pair. International Journal of Social Science and Humanities Research, 2, 279-283.

[23] Shefeeni, J.P.S. and Mabakeng, M.E.P. (2014) Examining the Weak Form Efficiency in Foreign Exchange Market in Namibia. International Review of Research in Emerging Markets and the Global Economy.

[24] Makorvsky, P. (2014) Modern Approaches to Efficient Market Hypothesis of FOREX-The Central European Case. Procedia Economics and Finance, 14, 397-406. https://doi.org/10.1016/S2212-5671(14)00728-X

[25] Mabakeng, M.E.P. (2015) Investigating the Semi-Strong Efficiency in Namibia's Foreign Exchange Market. Global Journal of Contemporary Research in Accounting, Auditing and Business Ethics.

[26] Cicek, M. (2014) A Cointegration Test for Turkish Foreign Exchange Market Efficiency. Asian Economic and Financial Review, 4, 451-471.

[27] Kumar, A.S. (2016) Efficiency, Non-Linearity and Chaos: Evidences from BRICS Foreign Exchange Markets. Theoretical and Applied Economics, 1, 103-118.

[28] Mauritius Commercial Bank. http://www.mcbgroup.com/en/group/economy-and-finance/economy-and-finance

[29] Phillips, P.C.B. and Perron, P. (1988) Testing for a Unit Root in Time Series Regression. Biometrika, 75, 335-346. https://doi.org/10.1093/biomet/75.2.335

[30] Granger, C.W.J. (1980) Testing for Causality: A Personal Viewpoint. Journal of 
Economic Dynamics and Control, 2, 329-352.

https://doi.org/10.1016/0165-1889(80)90069-X

[31] Brooks, C. (2008) Introductory Econometrics for Finance. 2nd Edition. https://doi.org/10.1017/CBO9780511841644 